\title{
Pequenas ações de interdição e expulsão no território: [tecno] ideologias de metas políticas e sociais
}

\author{
Small actions of interdiction and removal from the territory: [Techno] ideologies behind political \\ and social objectives \\ Pequeñas acciones de interdicción y expulsión en el territorio: [tecno] ideologías de fines políticos y \\ sociales
}

\section{Resumo}

Territórios controlados por Estados estão sujeitos a estriamentos apriorísticos por meio de normatizações genéricas para poder assim ordená-los e facilitar eventuais interdições. Em contraponto, há a possibilidade de alisamentos destes mesmos espaços, tornando-os disponíveis a apropriações imprevistas. Estamos diante de uma dualidade entre dominação e espontaneidade, entre os aparelhos de captura e as máquinas de guerra, pares heterônimos de Gilles Deleuze e Félix Guattari. Juntamente a uma lógica urbana hostil, que evidencia o hóspede indesejável e marca os territórios com autoridade, opressão, regras e segregação — através de pequenas ações de inibição e coerção territorial por meio de leis, atos e arquiteturas hostis —, também há os espaços de hospitalidade, receptáculos abertos e lugares acolhedores que dão sempre lugar ao outro, a qualquer outro - tais como a Khôra, segundo Jacques Derrida —, e que ressaltam o direito à vida e os enfrentamentos a esses estriamentos. Amparado por esses conceitos, evidenciam-se territorializações construídas pela antinomia entre a imposição de controle, a partir do poder e medo, e a chance de acolhimentos constituidores de insondáveis compartilhamentos.

Palavras-chave: Arquitetura hostil; Territórios; Hostipitalidade; Resíduos; Khôra.

\begin{abstract}
State-controlled territories are subject to aprioristic striations through general norms so that they may be ordered and thus eventually more easily interdicted. On the other hand, such spaces may be smoothed, making them available for unforeseen appropriations. This is the duality of domination and spontaneity, between the capturing apparatuses and the war machines, Gilles Deleuze and Felix Guatarri's heteronymous pairs. Concomitantly to a hostile urban logic, that places the unwanted guest in the spotlight and marks territories with authority, oppression, rules and segregation — through little territorial actions of inhibition and coercion by means of laws, acts and hostile architectures —, there are also places of hospitality, open receptacles and welcoming places that always make room for the other, any other — such as Khôra, according to Jacques Derrida - , and that points out the right to life and the confrontment to these striations. Using these concepts, it is possible to see the territorializations built from the antinomy between the imposition of control through power and fear and the chance to be welcoming and thus promote unfathomable sharing processes.
\end{abstract}

Keywords: Hostile architecture; Territories; Hostipitality; Residue; Khôra.

\section{Resumen}

Territorios controlados por Estados están sujetos a estriamientos apriorísticos por medio de normatizaciones genéricas para que puedan, así, ordenarlos y facilitar eventuales interdicciones. Como contrapunto, está la posibilidad de alisamiento de estos mismos espacios, volviéndolos disponibles para apropiaciones imprevistas. Estamos frente a una dualidad entre dominación y espontaneidad, entre los aparatos de captura y las máquinas de guerra, pares heterónimos de Gilles Deleuze y Félix Guattari. Junto a una lógica urbana hostil, que evidencia el huésped indeseable y marca los territorios con autoridad, opresión, reglas y segregación - a través de pequeñas acciones de inhibición y coerción territorial por medio de leyes, acciones y arquitecturas hostiles — también están los espacios de hospitalidad, 
receptáculos abiertos y lugares acogedores que siempre dan lugar al otro, al cualquier otro — como Khôra, según Jacques Derrida - y que resaltan el derecho a la vida y los enfrentamientos a esos estriamientos. Respaldado por estos conceptos, se evidencian territorializaciones construidas por la antinomia entre la imposición del control, a partir del poder y del miedo, y la posibilidad de la acogida, constituyendo insondables intercambios.

Palabras clave: Arquitectura hostil; Territorios; Hostipitalidad; Residuos; Khôra.

\section{Introdução}

$\mathrm{O}$ artigo se desenvolve por meio de reflexões sobre as pequenas ações de interdições e opressões nos territórios se contrapondo aos agentes e às tomadas dos espaços que se opõem ao Estado e suas máquinas de guerra, através dos alisamentos dos sítios e dos acolhimentos por parte do coletivo. Levanta-se assim uma dualidade entre guerra e paz que evidencia as apropriações e expropriações dos microterritórios das mais variadas formas, notabilizando os vazios urbanos e marquises.

O poder que depende da violência [ou do medo] não representa [ou representam] o poder máximo: o simples fato de que uma vontade contrária surja e se oponha àquele que o detém é a prova da fraqueza do seu poder. O poder está precisamente onde não é posto em evidência. Quanto maior é o poder, mais silenciosamente atua. Ele se dá sem ter que apontar ruidosamente para si mesmo. (Han, 2020, p. 25)

\section{Objetivo geral}

Pretende-se trazer questionamentos sobre os direitos à vida, primordialmente, e à cidadania, como condições sine qua non para a construção de uma justiça social que vá além dos fundamentos e limites do direito jurídico. Tal construção passa pelo exercício da construção de si por meio de uma disponibilização daquilo que é ou está indisponível através de uma ação voluntária, prática de uma vontade de potência singularizante, direta, sem intermediações, sem máquinas ou maquinações interpostas.

\section{Objetivo específico}

Evidenciar as pequenas ações de inibição e coerção nos territórios, sejam elas engendradas de maneiras sutis ou não, através de leis, ações e arquiteturas hostis, expondo-as de um modo que, a partir delas, seja possível fomentar indagações a respeito dos processos pelos quais movimentos antagônicos emergem a partir de um desejo de estar e atuar no mundo para além do que, a priori, se coloca ou é colocado como [in]disponível.

\section{Metodologia}

Através da ancoragem em alguns conceitos da filosofia contemporânea, sobretudo francesa, baseado em método cruzado e transdisciplinar de pesquisa bibliográfica, propõe-se uma reflexão crítica ampliada, confluências, acerca de improváveis e [in]oportunas micro-territorializações em espaços centrais da metrópole contemporânea. O texto está dividido em três partes. A primeira apresenta as técnicas hostis utilizadas e abordadas de diferentes maneiras no território brasileiro em um período de quase 30 anos, com ênfase nas mais recentes manifestações dessas técnicas e procedimentos. A segunda parte busca posicionar os territórios, a 'hostipitalidade' territorial e o modo como o Estado [inter]age nos espaços, através de conceitos advindos sobretudo da filosofia francesa fin de siècle, como os de estriamento e alisamento, abordados por Gilles Deleuze e Félix Guattari; questões sobre o poder e os processos de subjetivação, debatidas por Michel Foucault. Já na terceira, a discussão aproxima-se das noções de hospitalidade e acolhimento a partir de conceitos como Khôra, conforme Jacques Derrida problematiza, destacando as questões do poder e controle como, ao mesmo tempo, contrapontos e emuladores à vontade e luta por hospitalidade a partir do reconhecimento de alguns sujeitos agenciadores de apropriações receptivas e abertas ao outro e às imprevistas coletividades reterritorializantes. 


\section{Resultados e Discussão}

\section{Microtécnicas hostis, produção de hospitalidade inóspita}

Preâmbulo necessário; não há qualquer intenção aqui em se fazer uma apologia do precário, apesar da precarização ser um movimento constante alimentado pelo mundo neoliberal. A produção do precário é uma forma de se justificar a necessidade de eliminação ou apagamento do indesejável, e este processo de apagamento do indesejável pela interdição tornase o nosso assunto.

Feita tal ressalva, podemos dizer que não é de hoje que usamos a arquitetura e o design para criar espaços 'hostipitaleiros' (neologismo criado pelo filósofo Jacques Derrida para expressar movimentos e processos de pseudoacolhimentos), ou seja, falsamente hospitaleiros, lugares de indesejáveis presenças, interdições necessárias à consumação da cidade, no amplo sentido do termo.

São técnicas usadas para demonstrar o incômodo com a presença do outro, seja ela por pouco ou muito tempo, afirmando que ali não é um lugar para alguns ou que é um lugar de permanência rápida, elas se fazem presentes em canteiros de flores, bancos, muretas, baixos de viaduto, grades, marquises, entre muitos outros exemplos. A arquitetura hostil impõe o desejo de uma pequena parcela e afeta a muitas pessoas, uma maneira de afastamento e, podemos dizer, de higienização.

Não obstante, a arquitetura hostil se apresenta em São Paulo, tendo como caso bastante emblemático, a situação envolvendo o Padre Júlio Lancellotti, que quebrou a marretadas os pedregulhos colocados pela prefeitura sob o viaduto Dom Luciano Mendes de Almeida, na zona leste da cidade, para impedir que moradores de rua se abrigassem. A prefeitura de São Paulo, então sob o comando de Bruno Covas, não foi a primeira e, possivelmente, não será a última a aplicar esse tipo de arquitetura, assim como não foi a primeira ação de oposição a essa arquitetura tomada pelo Padre Júlio Lancellotti, que já em 1994 lutava contra o Projeto de Lei Câmara Municipal 11.623/94, sancionado posteriormente pelo então prefeito Paulo Maluf, que controlava o uso dos baixos dos viadutos e pontes de São Paulo, podendo então desalojar moradores que ocupavam essas áreas, desta forma movendo os moradores de rua e maquiando a cidade (Folha de S. Paulo, 1994).

Como pode ser visto em matéria do dia 4 de setembro de 1994 na Folha de São Paulo, era comum ser colocado óleo no piso e na porta de ferro para que moradores de rua não permanecessem junto a um estabelecimento durante a noite na região central de São Paulo, ou então evitava-se a construção de marquises em prédios novos para não servir de abrigo a moradores de rua (Filho, 1994). Essa expulsão ocorre de formas diferentes hoje, quando em baixos de vias elevadas e marquises são colocadas luzes que ficam a noite toda ligadas, ou jatos d'água que se ligam de tempos em tempos, assim como o próprio descaso da manutenção de marquises para que haja vazamentos, ou, no limite, a remoção dessas marquises. Mudam ações e contextos, mas a hostilidade está sempre presente.

A própria tática de pedregulhos sob viadutos aconteceu em outros momentos, como durante a gestão do prefeito Gilberto Kassab, em 2011, sob o viaduto Cruzeiro do Sul, que faz parte do trajeto da linha azul do metrô, especificamente entre os trechos Portuguesa-Tietê e Santana. Após a inauguração do MAAU (Museus Aberto de Arte Urbana), em 2012, a área começou a ser gradeada, em oposição ao que a maioria dos moradores e comerciantes da região queria. A subprefeitura e o metrô não assumiram a responsabilidade pelo pedido e a obra foi embargada, sendo assim, as grades foram retiradas (Teixeira, 2014). Porém, após a tentativa fracassada de gradeamento, ao longo deste trecho do baixo, pedregulhos foram instalados nos pés das colunas de sustentação onde os grafites foram feitos, afastando assim moradores de rua e produzindo uma dualidade entre a livre expressão do grafite e tomada de espaço contra a higienização do local.

Com a forte difusão e repercussão da notícia das marretadas do Padre Lancellotti nos pedregulhos colocados sob o viaduto Dom Luciano Mendes de Almeida no ano de 2020, a discussão sobre a arquitetura hostil e hospitalidade da cidade retornou com potência, ainda mais nesse momento em que fomos arrebatados pela pandemia de COVID-19. À frente da 
paróquia São Miguel Arcanjo, na Mooca, e na linha de frente pelos moradores de rua, o Padre Lancellotti já era contra e debatia sobre essas questões desde pelo menos sua reação à supracitada Lei de 1994 (Folha de S. Paulo, 1994). Vale apontar que essa situação vem acontecendo há tempos na cidade e em diversos lugares, como uma maquiagem sobre esses lugares residuais. Contudo, o problema vai muito além da apropriação do lugar, tendo como principal questão a definição de quem e como se pode usufruir desses espaços.

Outro evento que também teve repercussão aconteceu em dezembro de 2021, na cidade de Campinas, em São Paulo, onde o Padre Lancellotti, por meio de suas mídias sociais e através do seu afinco de expor este tipo de arquitetura, fez uma denúncia sobre espetos de ferro instalados em uma das escadas da Catedral Metropolitana de Campinas. Após a exposição do caso, os responsáveis pela Catedral retiraram os elementos que estavam instalados no local desde 1990.

Não é incomum encontrar espetos pontiagudos, grades, pregos ou outros meios junto de vitrines, sobre muretas e escadas com potenciais de uso ou de abrigo. Versões de uma espécie de apartheid territorial proliferam como antípodas ao candente e premente direito à cidade. Lojas, comércios, bancos, prédios corporativos, entre outros que têm suas frentes voltadas diretamente para a rua, fazem uso desses artifícios para barrar a permanência dos sujeitos indesejados por eles e contam com essa prática, cada vez mais comum em um mundo tomado por « higiênicas » brutalidades.

Para além de São Paulo, a aplicação da arquitetura hostil ocorre em diversas partes do Brasil, como em Porto Alegre, onde moradores instalaram canos furados embaixo da marquise de um prédio e ligam a água para vazar nas pessoas que ali se abrigam. Na mesma cidade, grades foram colocadas na calçada em frente a um prédio para que os moradores de rua não se instalassem no local (Favero, 2014). Algo semelhante aconteceu no Rio de Janeiro, no bairro de Copacabana, onde um condomínio instalou jatos de água em sua marquise para respingar e afastar as pessoas que se refugiem no local (Costa, 2017).

A arquitetura hostil, com suas grades, muros, bancos com definições de assentos, entre outros elementos, bloqueia o direito das pessoas de usufruírem com liberdade dos espaços que, para muitos, é abrigo e, para outros, descanso, passagens, encontros ou possibilidades. É uma arquitetura higienista, segregadora, que remete à exclusão e ao medo. Parte de propostas elitistas para maquiar a realidade da cidade, onde o poder aquisitivo, o mercado imobiliário e as especulações são fatores dominantes para decisões urbanísticas.

A hostilidade é presente diariamente, e a repulsa às pessoas através de mobiliários urbanos é um problema que vai muito além do uso, ela cria uma segregação de quem e como pode-se utilizar áreas públicas abertas.

Os sujeitos se expropriam ou são expropriados de acordo com as demandas e necessidades que surgem a partir do controle do Estado, porém, como Hegel discorre sobre o conceito de notrecht ${ }^{1}$, o direito à vida se sobrepõe a qualquer outro direito, inclusive ao de propriedade, o que nos faz refletir sobre as apropriações dos espaços em desuso para moradia, sem dispor uma exclusão ou demolição desses espaços, mas sim uma reforma, um aproveitamento desses lugares que estão ociosos, e que, para muitos, são uma oportunidade.

Uma proposta de lei relacionada à técnica de exclusão da arquitetura hostil foi tramitada pelo senador Fabiano Contarato (REDE-ES), a PL 488/2021, que proíbe o uso da “arquitetura hostil” em espaços livres de uso público no território brasileiro e que foi aprovada pelo Senado e segue agora para Câmara dos deputados. O próprio projeto de lei menciona alguns exemplos que o arquiteto e urbanista Nabil Bonduki descreve:

Espetos e pinos metálicos pontudos; pavimentações irregulares; plataformas inclinadas; pedras ásperas e pontiagudas; bancos sem encosto, ondulados ou com divisórias; regadores, chuveiros e jatos d'água; cercas eletrificadas ou de

\footnotetext{
${ }^{1}$ Notrecht segundo Hegel é o direito de necessidade, “[...] um direito que cada um tem de abrir uma exceção a seu favor, em caso de extrema necessidade. Mas isso não pode ser definido a priori. São as circunstâncias que o determinam. Estando em conflito, por exemplo, o direito à vida e o direito de propriedade, aquele se impõe." (Weber, 2018, p.304)
} 
arame farpado; muros altos com cacos de vidro; plataformas móveis inclinadas; blocos ou cilindros de concreto nas calçadas; dispositivos "anti-skate". A lista é longa e está incompleta. (Bonduki, 2021)

Graças à grande repercussão das marretadas do Padre Júlio Lancellotti, essa lei emergiu. Se aprovada, a ideia é nomeá-la com o nome do pároco. Isso mostra que apenas a grande reverberação da situação pôde trazer este assunto à tona, algo que já deveria ter sido superado e trabalhado com políticas públicas, visto as datas dos relatos contrários à tal técnica e os princípios básicos civilizatórios desrespeitados por sua aplicação. Muda-se a gestão, mas a forma de tratar essas questões são sempre as mesmas, segregadoras e higienistas, refletindo como os territórios se comportam e como o Estado age para fundar esse comportamento. É, afinal, uma lei que precisa ser aplicada para que uma cidade, ou melhor, para que o território brasileiro não seja excludente, já que o Estado deveria garantir a hospitalidade em vez de praticar a 'hostipitalidade', sem precisar que para isso se tenha ações de revolta e grande repercussão midiática. Afinal, “a funcionalidade da democracia em sua versão fetichizada parece servir indistintamente a todos, mas serve em verdade aos que precisam dela para legitimar a sua denominação.” (Dantas, 2017, p.218).

A seguir, apresenta-se a Figura 1, que retrata o Baixo do viaduto Dom Luciano Mendes de Almeida após a intervenção do padre Júlio Lancellotti, quando a área foi limpa e grafites surgiram no local, dois deles com as frases: "Menos pedras e mais moradia!!!" e "Tinham pedras no meio do caminho".

Figura 1. Baixo do viaduto Dom Luciano Mendes de Almeida.

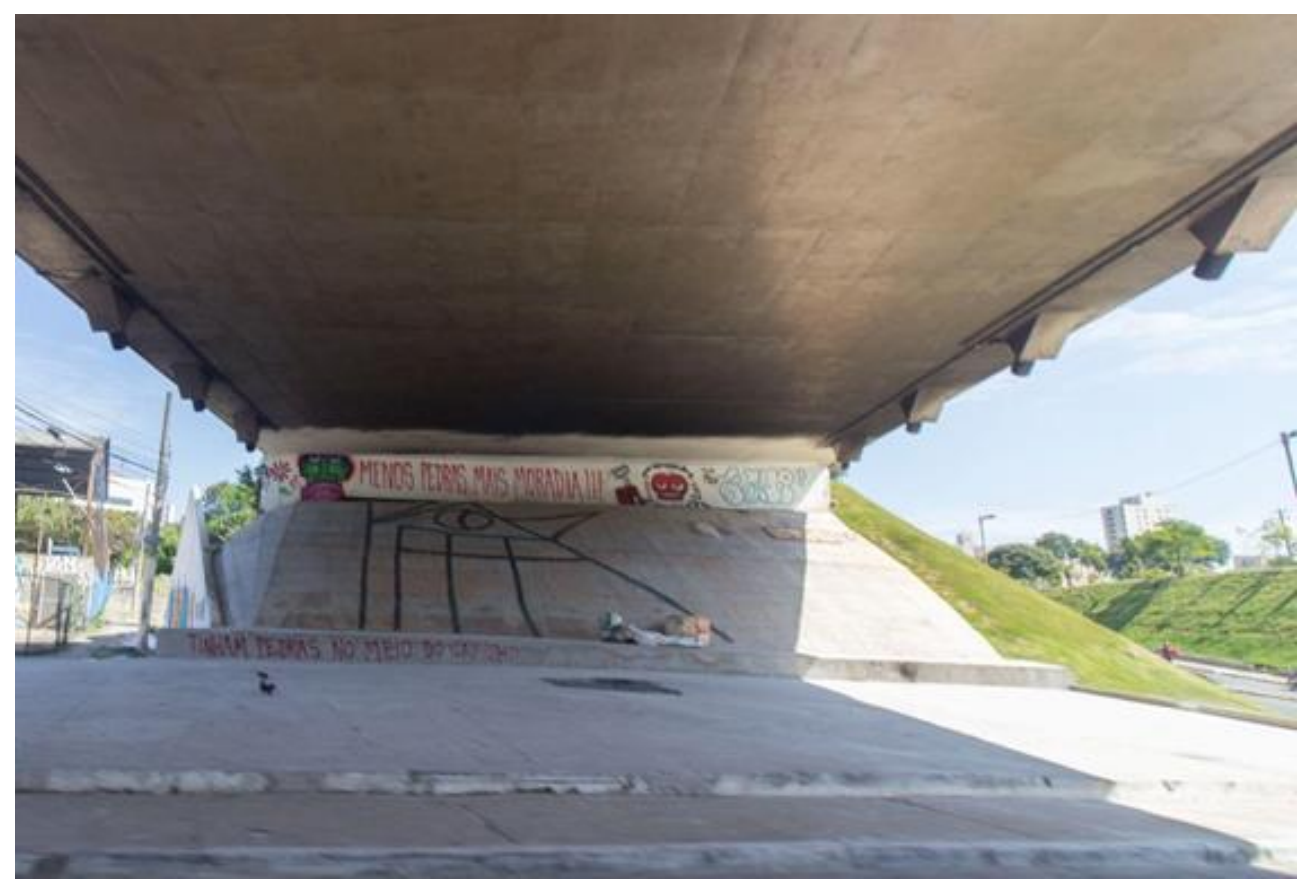

Fonte: Autoria própria.

\section{Territórios e o exercício da [não] hospitalidade}

Territórios, espaços delimitados e controlados por poderes estabelecidos, que impõem e determinam o que é permitido ou não, muitas vezes baseados em leis e regras que não são aplicadas da mesma forma para todos “[...] Foucault precisa: território é uma noção geográfica, mas, antes de tudo, uma noção jurídico-política (designa o que é controlado por determinado tipo de poder)" (Castro, 2016, p.414). Como e para quem essas áreas estão disponíveis, se abertas da forma mais ampla possível, tal como os espaços residuais, brechas urbanas sem usos a priori, vazios que muitas vezes estão latentes por novas possibilidades. 
Os sítios, em sua maior parte dominados e controlados pelo Estado, existem como espaço estriado², "mede-se o espaço a fim de ocupá-1o" (Deleuze \& Guattari; 2012, p.26). Desta forma, há uma organização, como uma rédea a partir da qual as peças ficam de acordo com o programado. Porém, outras vezes isso não é possível, gerando territórios não domados pelo Estado, sendo assim, lisos ${ }^{3}$ — “ocupa-se o espaço sem medi-lo" como Deleuze e Guattari denominam (Deleuze \& Guattari, 2012, p.26) e nos fazem refletir sobre as lacunas nessas áreas - territórios estranhos que, a princípio, não têm um significado, sem métricas, lisos à espera de algo ou alguém. E é nesse momento em que as condições mudam, e quando acontecem essas imprevistas apropriações em uma área, ela deixa de ser um espaço [in]disponível e passa a ter um sentido.

Quando o Estado não está de acordo, essa área começa a criar um ruído diferente, esta apropriação, seja da maneira que for, passa a ser recusada por alguém, “... o Estado consiste em estriar o espaço, contra tudo que o ameaça transbordá-lo" (Deleuze \& Guattari; 2012, p.64), ao que se pode completar com o que Foucault escreve:

[...] coloca o problema da visibilidade, mas pensando em uma visibilidade organizada inteiramente em torno de um olhar dominador e vigilante. Ele [Bentham] faz funcionar um projeto de uma visibilidade universal, que agiria em proveito de um poder rigoroso e meticuloso. (Foucault, 2012, p.215)

Assim, os limites dos territórios ficam definidos, alinhados e monitorados para que não se fuja do que o Estado permite dentro das suas demarcações.

Não é possível estriar uma cidade por inteiro; existem sempre espaços lisos, eles podem surgir, serem transformados, mudarem de lugar, mas sempre existirão. Essas áreas incômodas, que muitas vezes podem causar estranhamentos, preocupações e receios, mas que, no entanto, são essenciais para um território, pois nos fazem pensar e refletir sobre os espaços que não têm uma denominação a priori.

Quando há um espaço em desuso, vazio, como um Terrain Vague 4 , por que não se apropriar, tomar como lugar para si, dar um significado, mesmo que momentâneo, de diversas formas? Contudo, isso tem um preço. Quando acontece, quando há uma apropriação, no mesmo instante ocorre a expropriação, ou seja, ele deixa de ser de um e torna-se do outro. Apropriar-se de algo, apoderar-se de uma área, no que e em quem isso pode interferir, essa expropriação, pode intervir no entorno.

Uma apropriação coletiva, individual, seja qual for, gera uma desordem em um sítio que o Estado quer que seja controlado. Em uma sociedade que em teoria é livre e regida por leis que deveriam ser aplicadas de forma homogênea isso não acontece, e este mesmo conceito ocorre quando se designa para a cidade territórios, sem entrar no mérito de propriedade privada.

O acesso e o uso não são receptivos a todos, os usos dos espaços não se dão e não são vistos da mesma forma dependendo de quem os usa e para quem ou o que ele influencia. O Estado parece preferir a existência de espaços em desuso àqueles com novos significados quando não são ordenados por ele e, dessa forma, ocorrem as reapropriações ou bloqueios dessas áreas, sem deixar que isso aconteça novamente.

A questão para o Estado é a expropriação, quando alguém se apropria do que estaria sob o controle dele sem sua autorização, como uma posse. A partir desse ponto, algo sai do seu comando, do seu espaço estriado e começa a ter uma nova dinâmica fora do idealizado. Em muitos casos, quando é do seu interesse, essa apropriação do outro não se torna um problema,

\footnotetext{
${ }^{2}$ Espaço estriado, segundo Deleuze e Guattari, se daria a partir de “[...] relações biunívocas entre si e com as do adversário: suas funções são estruturais. [Espaço] regrado, codificado, com uma fronte, uma retaguarda, batalhas." (Deleuze \& Guattari; 2012, p.14).

${ }^{3}$ Espaço liso, segundo Deleuze e Guattari “[...] são os elementos de um agenciamento maquínico não subjetivado, sem propriedades intrínsecas, porém apenas de situação. [...] sem afrontamento e retaguarda, no limite sem batalha: pura estratégia..." (Deleuze \& Guattari; 2012, p.14).

${ }^{4} \mathrm{O}$ conceito de Terrain Vague foi criado pelo arquiteto e filósofo Ignasi de Solà-Morales: "A relação entre a ausência de uso, de atividade e o sentido de liberdade, de expectativa, é fundamental para entender toda a potência evocativa que os terrain vague das cidades tem na percepção da mesma nos últimos anos. Vazio, portanto, como ausência, mas também como promessa, com o encontro, como espaço do possível, expectativa." (Solà-Morales, 2003, p.185).
} 
porém, quando é em um território importante para o Estado, ela se torna uma disputa, ou melhor, uma remoção e desapropriação.

Uma apropriação espontânea em um espaço em desuso, como uma brecha que surge para ocupar esses territórios que estão abertos ao devir, às possibilidades e urgências que os sujeitos demandam, preenchendo as lacunas que as cidades deixam expostas.

Da cidade, uma área geográfica compilada de pessoas, temos a ideia inicial de que seja hospitaleira, principalmente quando a denominamos como lar, porém para alguns é o inverso. A hostipitalidade ${ }^{5}$, contra o hóspede indesejável, é, muitas vezes, a forma como o Estado trata os sujeitos que habitam esses territórios. Na maioria dos casos, a minoria é tratada dessa forma, como inconveniente, quando não se comporta dentro de padrões estabelecidos pelo poder, quando ocupa espaços que não eram definidos a priori para tal função, espaços esses muitas vezes residuais da cidade, porém não receptivos quando para o Estado não lhe convém.

O Estado age de forma agressiva quando o território sai do seu controle. Essa forma hostil de manter o poder está ligada às máquinas de guerra que se articulam de diversas formas a fim de reorganizar o território. Essa forma de dominação e hostilidade para combater seu adversário, que na verdade são os próprios sujeitos que compõem e habitam as cidades administradas por ele, é uma forma de hostipitalidade que age para manter sempre o domínio sobre quem não seguir as regras do jogo criado e manipulado por ele.

As próprias máquinas de guerra ${ }^{6}$ são peças articuladas e bem planejadas pelo Estado. Elas também são controladas e meticulosamente articuladas de acordo com as necessidades, agindo como se tivessem o poder, mas não passam de peças de um jogo bem estruturado.

À guerra ou às hostilidades, à hostilidade, quer dizer, a uma hostilidade declarada que é também, acredita-se comumente, o contrário da hospitalidade. Ora, se a guerra e a hostilidade declarada fossem a mesma coisa, e se fossem o contrário da paz, dever-se-ia dizer que paz e a hospitalidade do acolhimento vão também juntas. E que elas formam um par inseparável, uma correlação na qual uma, a paz, corresponde à outra, a hospitalidade, ou reciprocamente. (Derrida, 2008, p. 105).

A hostilidade se mostra em diversos momentos pelos controladores. É, a partir da opressão, do medo, que o Estado impõe e mostra às outras pessoas os limites que ele suporta, escancarando o que não é permitido por ele, para assim dar como exemplo aos sujeitos que pensam e agem diferente do idealizado pelos administradores dos territórios. Essa relação de dominação através de mecanismos de poder, conforme escreve Foucault, “...trata-se de utilizar a organização do espaço para alcançar objetivos econômicos-políticos” (Foucault, 2012, p.211). Estriando os espaços, criando agentes controladores, impondo seu poder através do medo, expondo os sujeitos e os deixando visíveis a fim de melhor observá-los para poder então dominá-los e manipulá-los da maneira que for mais conveniente. "No panopticon, cada um, de acordo com seu lugar, é vigiado por todos ou por alguns outros; trata-se de um aparelho de desconfiança total e circulante, pois não existe ponto absoluto. A perfeição da vigilância é uma soma de malevolências. (Foucault, 2012, p.220).

O panopticon é sinônimo de disciplina, e hoje podemos dizer que não é somente o Estado quem vigia e controla. É ele quem governa, porém, a própria sociedade faz isso com os sujeitos que não agem de acordo com um determinado grupo, como as iniciativas de condomínios e lojistas para a produção de uma arquitetura hostil. Em microterritórios, os agentes que se

\footnotetext{
${ }^{5}$ Hostipitalidade - "[...] uma hospitalidade hostil [...] uma hospitalidade onde o cidadão torna-se um hóspede quase indesejável em um lugar que deveria ser sua própria casa." (Guatelli, 2015, p.177)

${ }^{6}$ Máquinas de guerra: conceito de Deleuze \& Guattari onde os nômades se articularam, formando as máquinas de guerra, no qual a "A máquina de guerra opera fora do aparelho de Estado e da economia corporativa, fora dos dispositivos de estruturação e controle do espaço urbano.” (Brissac, 2002, p.11) porém, "[...] a máquina de guerra não tem por si mesma a guerra por objeto, mas passa a tê-la, necessariamente, quando se deixa apropriar pelo aparelho de Estado" (Deleuze \& Guattari, 2012, p.244).
} 
intitulam controladores desses espaços são os dominadores das regras, como em uma cadeia. Criam-se microterritórios com agentes que atuam naquela área, acima, outros agentes, que controlam alguns microterritórios, e assim sucessivamente, até chegar ao Estado. Esses agentes, vigiam e organizam, mas eles mesmos estão sendo observados e controlados, como por mecanismos coletivos de inibição (Deleuze \& Guattari, 2012, p.20).

O Estado só abre mão, ou melhor, só permite que certos desdobramentos com os territórios aconteçam quando convém, uma hospitalidade que é definida para grupos específicos em sua maioria, não é para todos e por todos. O que ocorre é uma hostipitalidade velada, um antônimo de acolhimento, que rejeita de diversas formas, algumas mais sutis, outras ostensivas (escancaradas), mas sempre presente, marcando territórios, escolhendo quem pode usufruir dele, como capilaridades do poder que se impõem diante de grupos.

O indivíduo (ou, de um modo geral, sujeito da pólis) pode ser considerado inconveniente dentro da sua própria cidade dentro dos limites que estabeleceram para defini-lo como parte daquilo. É antitético ao que de fato deveria ser, uma subversão de um modo ruim. O local que deveria hospedar impõe barreiras e repulsa de modo claro, como quem diz: aqui você não é bem-vindo, onde então ele será?

Se em sua própria delimitação, dependendo de seu grupo, não se faz questão de sua presença, pelo contrário. O sujeito fica à mercê de um outro que não quer sua presença ali. Como conseguir ocupar os espaços residuais se quem deveria possibilitar outras alternativas em vez dessa apropriação não quer e prefere maquiar a cidade, impor limites e áreas, afastar em vez de ser um apoio? Resistir e apropriar-se é necessário para remanescer.

\section{Receptáculos de acolhimento}

Uma cidade hospitaleira, em vez de hostipitaleira, acolhedora, como um receptáculo, disponível a novas significações, contrária a oprimir e organizar, seria um território aberto, contra definições. Os espaços sem julgamento, atemporal, se fazem e refazem quantas vezes necessárias, são a aceitação, seja para o que for ou para quem for, como $\mathrm{Khôra}^{7}$. Essa não imposição se permite a múltiplas possibilidades, ressignificações e interpretações. É sempre acessível e afável e também mutável. De acordo com o que que está acontecendo no instante, pode-se apagar e começar novamente, sem deixar rastros ou fissuras, é transitória, aberta ao novo, ao porvir.

São áreas mescladas entre espaços lisos e estriados, sem uma dominação opressora, mais hospitaleira:

A hospitalidade pura ou incondicional, a hospitalidade em si, abre-se ou está aberta previamente para alguém que não é esperado nem convidado, para quem quer que chegue como um visitante absolutamente estranho, como um recémchegado, não identificável e imprevisível, em suma, totalmente outro. (Derrida, 2003, p.15)

Territórios não excludentes, que aceitem suas demandas e sujeitos, com espaços organizados, mas também com lugares abertos ao porvir, que se deixem contaminar e descontaminar, que acolham as apropriações naturais, lugares que abriguem sem julgar, mesmo que sejam espaços que coincidam ou colidam.

Sentidos e significados são sugeridos, organizações e configurações espaciais adequadas às destinações exigidas estão presentes e garantem o funcionamento do conjunto, porém, dialogando e, por vezes, conflitando com o indefinido, com o seu contrário, com aquilo que pode estar aquém e além, não só de sua própria situação inicial pretendida no ato da projetação, como do conjunto todo. (Guatelli, 2006)

${ }^{7}$ Conceito de Jacques Derrida, “A khôra não é nem "sensível”, nem “inteligível”; ela pertence a um “terceiro gênero” (triton genos, 48e, 52a). Sobre ela não se pode nem mesmo dizer que ela não é nem isto, nem aquilo, ou que é ao mesmo tempo isto e aquilo.” (Derrida, 1995, p.09). 
Um Estado menos segregador e mais acolhedor, que respeite os sujeitos que habitam os territórios, como escreve James Hillman em seu livro Cidade \& Alma: “[...] uma cidade é construída sobre relações humanas” (Hilman, 1993, p.42) e não ordem sobre opressão, mas uma forma de estar aberta, ser abrigo, um receptáculo:

Trata-se de uma diferença irredutível que antecede as oposições entre ser e não-ser, identidade e diferença, próprio e impróprio, mesmo e outro. [...] daquilo que nunca é puro, que se deixa profanar permanentemente. [...] Khôra é o lugar do espaçamento. (Neto, 2011, p.06)

Deve-se aceitar, sem preconceitos ou pré-preenchimentos semânticos, as lacunas que as cidades abrigam para poder ter novas significações, apropriações ou o que estiver por vir, acolhendo assim as nuances dos territórios, deixando-os lisos para serem estriados, como um tabuleiro que comporta vários jogos, e a partir dos indivíduos que se envolvem nesses espaços. Lugares e indivíduos livres de pré-condicionamentos, livres o suficiente para agirem e para escolherem o que pretendem durante o próprio ato no espaço público, momento de construção de nossa liberdade.

As apropriações que inicialmente começaram irregulares e foram ganhando forma e força ao longo do tempo com a participação da sociedade são respostas dos sujeitos ao necessário, que por muitas vezes o Estado não vê ou ignora. Porém, a partir do movimento, um espaço vazio se torna algo muito maior e não há como não ver e não aceitar, como é o caso de coletivos ou sujeitos que coordenam ou geram algo para a comunidade, que se apropriam também daquele espaço, tornando assim essas lacunas em aberturas dispostas ao outro.

Nos territórios criam-se microterritórios, mesmo em espaços residuais, em bordas, em lugares estranhos, espaços de muitas formas, e, por que não, de acolhimento? Espaços hospitaleiros, comunidades, projetos sociais em baixos de viadutos, ocupações, são diversos exemplos de áreas de acolhimento, são lugares que esperam por novas significações, sem definições se abriram ao outro, como receptáculos, que transforma o lugar que muitas vezes contamina seu entorno, como um rizoma que vai penetrando nas brechas, encontrando espaços e novos caminhos.

Nas cidades existem muitos territórios dentro de um só, e eles podem se comportar se acoplando ou de formas distintas. Todos esses espaços, sejam como forem, são importantes para a formação de um todo, alguns organizados, outros abertos, cada qual com suas peculiaridades, mas nesses meandros, muitos espaços de acolhimento, pode ser de formas singelas, como um bebedouro aberto instalado na frente do prédio da Gazeta na Avenida Paulista (disponível na Figura 4), como um projeto social da academia de boxe sob o Viaduto Alcântara Machado (Figura 3), na zona leste de São Paulo, uma ocupação em um prédio abandonado no centro de São Paulo, como a ocupação 9 de Julho, cuja fachada está na Figura 2, enfim, diversas formas, das mais variadas dimensões, nos mostram como um território pode ser e é, em suas singelas e diversas demonstrações, acolhedoras e hospitaleiras, "Ser livre, portanto, não significa nada mais do que se realizar conjuntamente. Liberdade é sinônimo de comunidade bem-sucedida.” (Han, 2020, p.12). Eis aqui alguns exemplos: 
Research, Society and Development, v. 11, n. 3, e5411326223, 2022

(CC BY 4.0) | ISSN 2525-3409 | DOI: http://dx.doi.org/10.33448/rsd-v11i3.26223

Figura 2. Fachada da ocupação 9 de Julho.

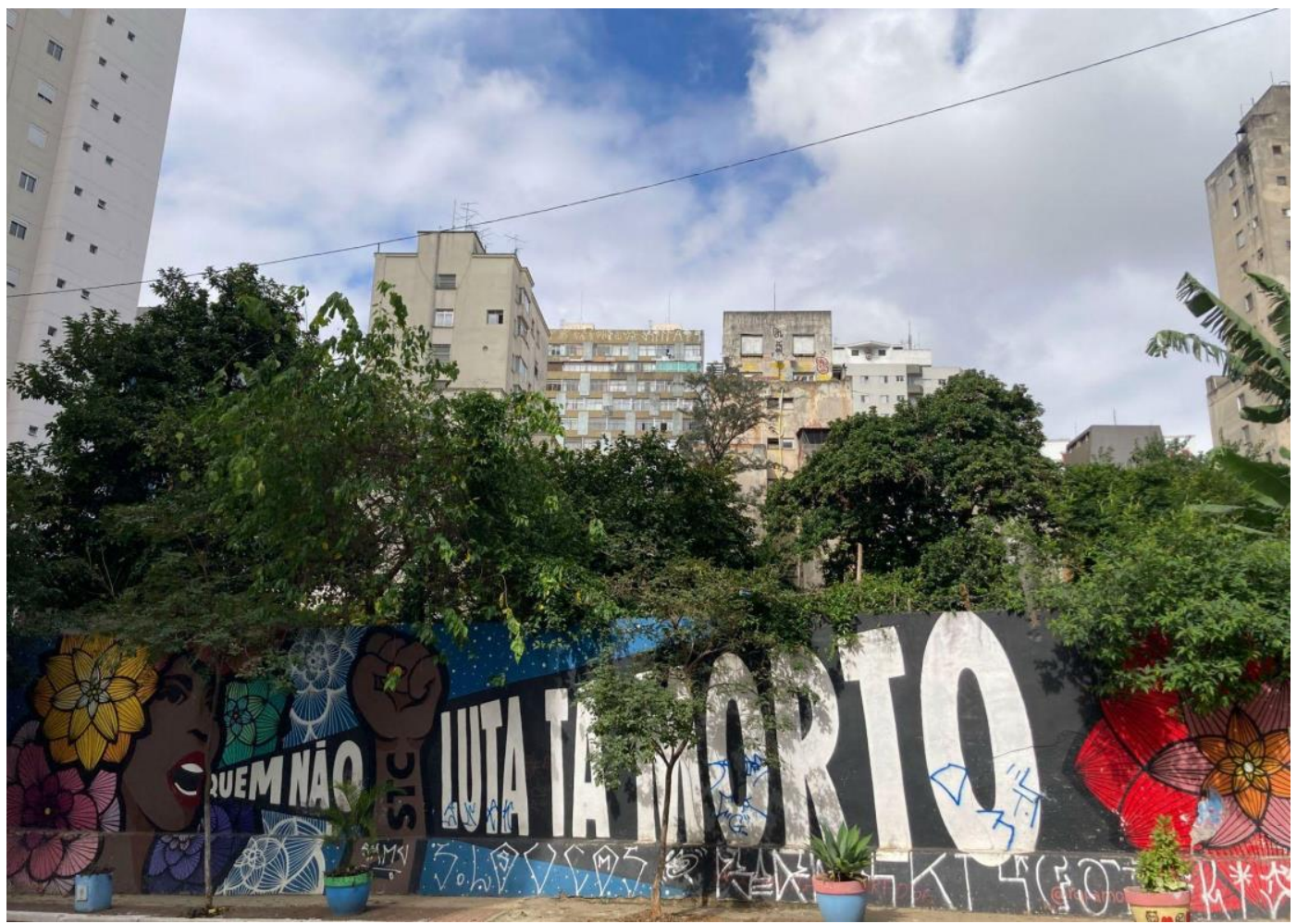

Grafite no muro da ocupação 9 de Julho com o escrito: “Quem não luta tá morto”. Fonte: Autoria própria.

Figura 3. Academia de boxe Nilson Garrido.

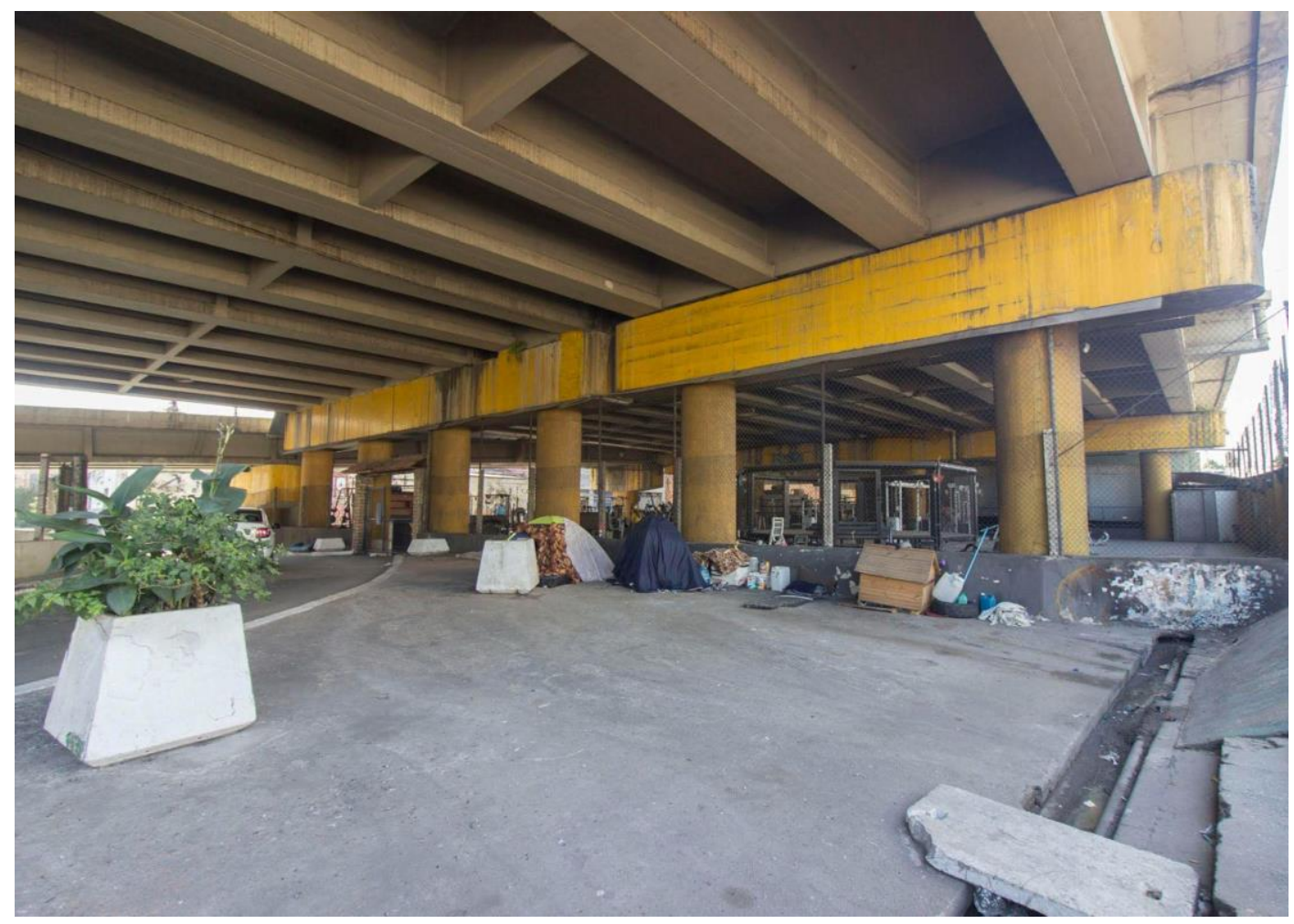

Baixo do viaduto Alcântara Machado, em uma das entradas para a academia de boxe Nilson Garrido. Fonte: Autoria própria. 
Figura 4. Bebedouro na Avenida Paulista.

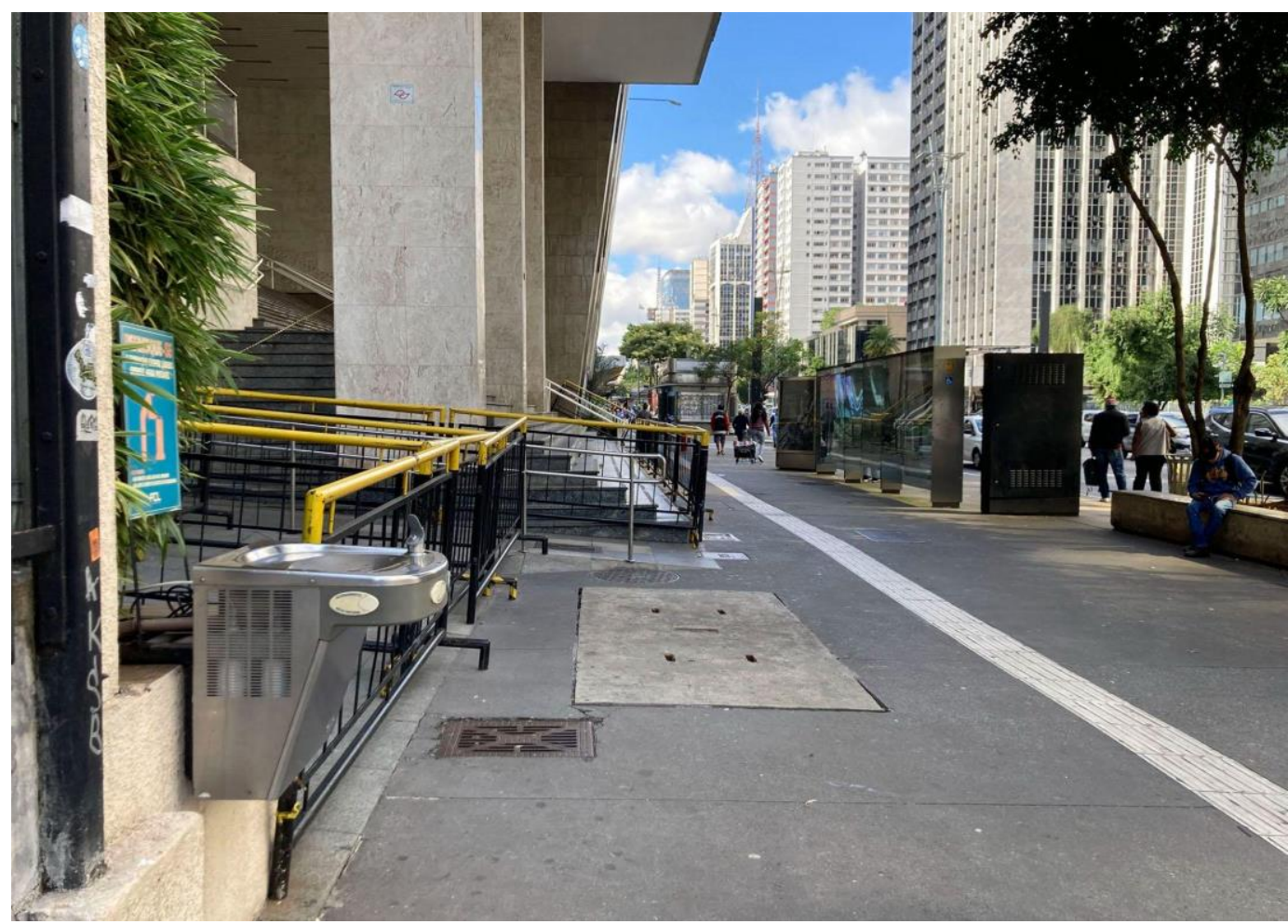

Bebedouro instalado em uma área aberta para a Avenida Paulista, de livre acesso a quem quiser usufruir. Fonte: Autoria própria.

\section{Considerações Finais}

Para o Estado, sua quase não presença é o meio mais eficaz de produzir a desigualdade e, consequentemente, manter o controle pela manutenção de uma ordem territorial naturalizada, capaz de caminhar, se possível, sem imprevistos. O excluído/indesejado procria o medo e a impotência, porém com ânsia de apropriação e, por vezes, com tomadas de espaços que, a priori, estão à deriva, em uma mescla de vontade de existência e desejos flutuantes, destituídos de um objeto preciso. Em certos momentos, os de dentro e os de fora se veem ocupando o mesmo território, em uma mistura de hostilidade e acolhimento.

Entre conflitos e concessões, territorialidades se compõem, áreas são tomadas, expropriadas, quebrando regras e se espalhando nos espaços lisos, de fluxos incessantes, como um rizoma. O rizoma só se forma na desordem, no acaso, na desestruturação, na multivocidade, traços de um acolhimento sem prescrições, mas, por ser volátil, instável, o rizoma é único e, dessa unicidade não reprodutível, há o instante que pode ser o momento do surgimento de algo para além de qualquer modelo. Talvez, então, não possa nunca ser tomado como exemplo, mas também nunca será substituível. O rizoma é a produção de instantes e de outras instâncias, de poder, do público, do comum, da democracia.

Para que esse instante ocorra, há a necessidade de que os sujeitos atuem. Essa ação política no território público será a responsável por esse momento único, singular, marginal, ou fora das margens, não mantendo-se, portanto, nos limites e lugares que lhes são concedidos ou que lhes resta, mas colocando-se nos lugares que lhes são de direito. Se abriria, dessa forma, um horizonte de outras experimentações de enlaçamentos e alianças sociais. Potencialmente singulares, talvez a ponto de desmanchar e dissolver hierarquias locais, por onde o incalculável emergiria como processo necessário à construção de uma outra democracia urbana ainda sem nomos, de outros espaços de direito, sequer previstos pelo próprio direito; opondo-se, frontalmente, ao Estado neoliberal permissivo que, por isso, a todos e tudo engendra. 
Ao mesmo tempo, através dessas imprevistas perturbações, novas micro ações atuariam nas brechas das sistematizações e hierarquizações territoriais que o próprio modelo cria, conserva e impõe, (des/re)codificando lógicas territoriais e as ações que as sustentam, mas sempre potencialmente desproporcional. Essas micro ações precisam ser desproporcionais ao modelo que as engendra para que possam atravessá-lo e deformá-lo, tarefa hercúlea para limites territoriais quase intransponíveis.

Como um rizoma, um emaranhado de linhas, mas com algumas pontas soltas, o desafio talvez seja o trabalho interminável de tornar possível aquilo que parece impossível dentro de lógicas hegemônicas. Encontrar e/ou provocar novas brechas nesses incessantes e hegemônicos movimentos de interdição e seletividade urbanas tornam-se o meio necessário pelo qual um porvir urbano democrático [quase] impossível pode aflorar como vitais e potentes anomalias.

\section{Referências}

Bonduki N. (2021) Precisamos de muitos Padres Júlios para combater a arquitetura hostil. Folha de São Paulo. https://www1.folha.uol.com.br/colunas/nabil-bonduki/2021/02/precisamos-de-muitos-padres-julios-para-combater-a-arquitetura-hostil.shtml.

BRASIL. Senado Federal. Projeto de $\quad$ Lei $\quad$ n $488 / 2021$. getter/documento?dm=8927525\&ts=1619046201037\&disposition=inline.

Brissac, N. (2002) As máquinas de guerra contra os aparelhos de captura. ARTE/CIDADE. http://www.artecidade.org.br/novo/publicacoes/fotonovela/maquinas_de_guerra_ebook_pt.pdf.

Castro, E. (2016) Vocabulário de Foucault - Um percurso sobre seus temas, conceitos e autores. Tradução de Ingrid Müller Xavier. Belo Horizonte, MG: Autêntica Editora.

Costa, L. (2017) Prédio é questionado por 'chuveirinho' para espantar morador de rua no Rio. Folha de S. Paulo. https://www1.folha.uol.com.br/cotidiano/2017/08/1907951-predio-instala-chuveiro-para-espantar-moradores-de-rua-na-zona-sul-do-rio.shtml.

Dantas, A. V. (2017). Do Socialismo à Democracia: tática e estratégia na Reforma Sanitária Brasileira. Editora Fiocruz.

Deleuze, G. \& Guattari, F. (2012) Mil Platôs. Editora 34.

Derrida, J. (1995) Khôra. Tradução de Nicia Adan Bonatti. Papirus.

Derrida, J. (2008). Adeus a Emmanuel Lévinas. Tradução de Fábio Landa. Perspectiva.

Derrida, J, \& Duformantelle, A. (2003) Da hospitalidade. Tradução de A. Romane. Escuta.

Favero, D. (2014) Prédio instala esguicho de água para afastar mendigos no RS. Portal Terra. https://www.terra.com.br/noticias/brasil/cidades/predio-instalaesguicho-de-agua-para-afastar-mendigos-no-

rs,a6682e95b6d59410VgnVCM4000009bcceb0aRCRD.html\#: :\%20text=Moradores\%20de\%20um\%20edif\%C3\%ADcio\%201ocalizado,embaixo\%20da\%20 marquise $\% 20$ do $\% 20$ pr\%C3\%A9dio.

Filho, A. R. (1994) Cidade cria arquitetura antimendigo. Folha de São Paulo. https://www1.folha.uol.com.br/fsp/1994/9/04/cotidiano/2.html.

Folha de S. Paulo (1994, 4 de setembro). Lei pode desalojar morador de ponte. https://www1.folha.uol.com.br/fsp/1994/9/04/cotidiano/10.html.

Foucault, M. (2012) Microfísica do Poder. Tradução de Roberto Machado. Edições Graal.

Guatelli, I. (2006) A marquise do Parque Ibirapuera e manifestação do conceito derridiano "entre”: arquitetura como suporte de ações. Vitruvius. São Paulo, Arquitextos, ano 06, n. 070.05. https://www.vitruvius.com.br/revistas/read/arquitextos/06.070/371.

Guatelli, I. (2015). A hospitalidade urbana e a multidão - uma discussão sobre soberania, estados de exceção e inclusão no espaço público urbano a partir de alguns processos de ocupação massiva do território na cidade. Revista do Programa de Pós-Graduação em Arquitetura e Urbanismo da FAUUSP. 22(38), 172-190.

Han, B. C. (2020) Psicopolítica - O neoliberalismo e as novas técnicas de poder. Tradução Maurício Liesen. ÂYINÉ.

Hillman, J. (1993) Cidade \& Alma. Tradução de Gustavo Barcellos e Lúcia Rosenberg. Studio Nobel.

Neto, F. L. (2021) Estaca “antimendigo” é retirada da catedral de Campinas após polêmica. https://www1.folha.uol.com.br/cotidiano/2021/12/estacaantimendigo-e-retirada-da-catedral-de-campinas-apos-polemica.shtml.

Neto, M. P. (2011) KHÔRA E ARKHÊ. EdiPUCRS. Semana Acadêmica do PPG em Filosofia da PUCRS - VIII Edição.https://editora.pucrs.br/anais/semanadefilosofia/VIII/1.23.pdf.

Solà-Morales, I. D. (2003) Territórios. Editorial Gustavo Gili, S.L. 
Research, Society and Development, v. 11, n. 3, e5411326223, 2022

(CC BY 4.0) | ISSN 2525-3409 | DOI: http://dx.doi.org/10.33448/rsd-v11i3.26223

Teixeira, R. (2014) Museu de grafite a céu aberto na zona norte de SP ganha mais 22 obras. Folha de São Paulo. https://www1.folha.uol.com.br/saopaulo/2014/02/1414805-museu-de-grafite-a-ceu-aberto-na-zona-norte-de-sp-ganha-mais-22-obras.shtml.

Weber, T. (2018) O direito de necessidade (Notrecht) como direito de dignidade: uma complementaridade entre Kant e Hegel. Direitos Fundamentais \& Justiça, 12(39), 299-312. 